\title{
Investigating the creep properties of asphaltic concrete containing nano-silica
}

\author{
HASAN TAHERKHANI ${ }^{1, *}$ and SIAMARK AFROOZI ${ }^{2}$ \\ ${ }^{1}$ Department of Civil Engineering, University of Zanjan, Zanjan 45371-38791, Iran \\ ${ }^{2}$ Department of Civil Engineering, Highway and Transportation Engineering, University of Zanjan, \\ Zanjan 45371-38791, Iran \\ e-mail: taherkhani.hasan@znu.ac.ir
}

MS received 1 February 2017; revised 27 May 2017; accepted 14 July 2017; published online 10 March 2018

\begin{abstract}
This study was aimed at investigating the creep behaviour of a typical asphalt concrete containing different percentages of nano-silica. The penetration grade of 60/70 asphalt cement was modified with different percentages of nano-silica (i.e., 1, 3 and 5\%, by the weight) and was used for making the asphalt concrete specimens. The asphalt concrete specimens were subjected to dynamic creep tests. Dynamic creep tests were conducted at different stress levels and temperatures. A three-stage model, developed was fitted to the dynamic creep test results to capture the primary, secondary and the tertiary creep regions, and calculate the flow number and the steady-state strain rate in the secondary creep region. The results showed that, the flow number increased, and the steady-state strain rate decreased with increasing nano-silica content, indicating the increase of resistance against permanent deformation.
\end{abstract}

Keywords. Asphalt concrete; nano-silica; dynamic creep; flow number; steady-state strain rate.

\section{Introduction}

For many years, when the loading on pavements was not severe, different neat asphalts (unmodified binders) were combined to improve their properties. However, in recent years, by the increase of traffic volume, use of heavier axle loads, new axle configurations and higher tire pressures, the demands on the highway pavements and asphaltic layers have increased, requiring the enhancement of the performance of the existing asphaltic materials [1-3]. Other reasons for introducing new modifiers in asphalt technology are due to the developments in technology, production of new materials and advances on the science of asphaltic materials. The modifiers that are available fall into various categories, such as naturally occurring materials, industrial by-products and waste materials, as well as carefully engineered products [3]. Some of the more common categories include reclaimed rubber products, fillers, fibers, catalysts, polymers (natural and synthetic) and extenders, to name a few [4]. Different types of polymers, including plastics and elastomers are among the widely used polymers. These have shown to improve the resistance of bitumen against fatigue cracking, permanent deformation and low temperature cracking [5]. Polymers have been reported to suffer from some limitations including the price, compatibility with bitumen, stability during storage and cost [3]. Due to these limitations, the use of alternative materials has attracted

*For correspondence the attention of engineers and researchers for improving the mechanical properties of bitumen and asphaltic mixtures.

In recent years, nanotechnology has become a promising and creative technique in the material industry, and nanomaterials have been widely applied to various fields across the world [6]. The Scientific Committee on Emerging and Newly Identified Health Risks (SCENIHR) defines nanomaterial as a material with one or more external dimensions, or an internal structure having one or more dimensions of the order of $100 \mathrm{~nm}$ or less, and which can exhibit novel characteristics compared to the same material without nano-scale features [7]. Many researchers have used nano-materials for cement, but the nano-material modified asphalt is relatively new when compared to its use in Portland cement concrete. Because of the very small size and huge surface area, nanomaterials can achieve the same effect of the ordinary material only by adding relatively little amount. There are various nano-materials, which have been or have potential to be used to modify asphalt, such as nano-clay, nano-silica, nanotitaniom, nano-hydrated lime, nano-sized plastic powders, or polymerised powders, nano-fibers, and nano-tubes, to name a few [8-13]. Among the nano-materials, nano-clay with its effects on the properties of bitumen and asphaltic mixtures have been investigated and shown to improve the rheological properties of bitumen and mechanical properties of the mixtures $[14,15]$. A low percentage of nano-clay has shown to increase the softening point and decrease the penetration and ductility of asphaltic binder. Nano-clay-modified asphalt 
has also shown to be more resistant against ageing [16]. Nano-clay modification improves the rheological properties of the binders by increasing the stiffness of asphalt and decreasing the phase angle (improves elasticity) when compared to conventional asphalt, hence this can also reduce the ageing effect [17]. For example, in some research work, it was found that $2 \%$ of nano-clay in the asphalt may increase the shear (complex) modulus by as much as $184 \%$ [12]. This indicates that the rutting resistance of such asphalt is likely to have been improved. This material has also been used as a secondary modifier to further enhance the performance properties of SBS-modified asphalt [18, 19]. Shafabakhsh and Jafari Ani used a combination of nano-titanium and nano-silica $\left(\mathrm{TiO}_{2} / \mathrm{SiO}_{2}\right)$ for modification of penetration grade bitumen and found that the nano-particles contributed to boost the rheological properties of the bitumen and improved the toughness and viscosity of the bitumen [11]. The use of modified bitumen in asphaltic mixtures containing steel slag aggregate showed that the resistance against rutting and fatigue cracking was improved [11]. Several studies have been conducted on nano-calcium carbonate (nano $\mathrm{CaCO}_{3}$ ) modified asphalt in China. Based on the results of these studies, both rutting resistance and the toughness of asphalt were improved by adding nano $\mathrm{CaCO}_{3}$. The results have shown that by adding nano $\mathrm{CaCO}_{3}$ to asphalt a uniform mixture was achieved and it was stable, while it reduced the susceptibility of asphalt to high temperatures $[20,21]$. Another nano-material, which can be used for modification of asphaltic materials is nano-silica. Silica is an abundant compound worldwide that is largely employed in industries to produce silica gels, colloidal silica, and fumed silica, etc. [22]. Nano-sized silica is interesting because it is applied in emerging areas like medicine and drug delivery [23]. Nano-silica particles have been used in the industry to reinforce the elastomers as a rheological solute [24] and cement concrete mixtures [25]. The advantage of these nano-materials includes the low cost of production and the high performance features [26]. According to Yao et al [6], nano-silica is also a material with a huge surface area, strong adsorption, good dispersal ability, high chemical purity and excellent stability. The use of $2-4 \%$ of nano-silica by the weight of asphalt binder has shown that it can reduce the rut depth by almost half $[6,12]$.

The survey of literature showed that limited research has been conducted on the effects of nano-silica on the mechanical properties of asphaltic mixtures. Specifically the creep behaviour of these mixtures is still unknown. Therefore, this study aims at investigating the performance of the nano-silica modified asphaltic concrete, focusing on the modelling of creep behaviour under dynamic loading.

\section{Research methodology}

\subsection{Materials}

The materials used in this research include asphaltic binder, aggregate and nano-silica. The penetration grade of 60/70 asphalt cement produced by Pasargad refinery has been used in this research. Table 1 shows the properties of the bitumen used in this study. Siliceous coarse, fine and filler were collected from an asphalt plant in Zanjan Province in north-west of Iran. Some preliminary tests were conducted on the coarse, fine and filler fractions to control the specification requirements and use in the mix design process. Table 2 shows the properties of the coarse, fine and filler fractions of the aggregate. Gradation test was also conducted on each fraction to determine the percentage of each in the mixture to achieve the target gradation. According to the specification in Iran for asphalt concrete, Gradation No. 4, which is a dense gradation, with the maximum aggregate size of $19 \mathrm{~mm}$ was used as the target gradation of the mixtures in this study. Figure 1 shows the specification limits and the gradation of the mixtures used in this study. Figure 2 shows the nanosilica particles and table 3 shows the chemical composition and the properties of the nano-silica used in this research.

\subsection{Research plan}

In this research work, the creep properties of asphaltic mixtures made by the modified binder was studied. The

Table 1. Properties of the bitumen used in this research.

\begin{tabular}{lrr}
\hline Test & \multicolumn{1}{c}{ Standard } & Results \\
\hline Density in $15^{\circ} \mathrm{C}$ & ASTM-D70 & 1.016 \\
Penetration in $25^{\circ} \mathrm{C}(0.1 \mathrm{~mm})$ & ASTM-D5 & 69 \\
Softening point $\left({ }^{\circ} \mathrm{C}\right)$ & ASTM-D36 & 49 \\
Ductility in $25^{\circ} \mathrm{C}(\mathrm{cm})$ & ASTM-D113 & 100 \\
Solubility in trichloroethylene $(\%)$ & ASTM-D2042 & 99.8 \\
Flash point $\left({ }^{\circ} \mathrm{C}\right)$ & ASTM-D92 & 308 \\
Loss in weight after thin film oven test $(\%)$ & ASTM-D1754 \\
Retained penetration after thin film oven test $(\%)$ & - & 0.03 \\
Ductility after thin film oven test $(\mathrm{cm})$ & - & 98 \\
Viscosity at $120^{\circ} \mathrm{C}$ (centistokes) & ASTM-D2170 \\
Viscosity at $135^{\circ} \mathrm{C}$ (centistokes) & ASTM-D2170 \\
Viscosity at $150^{\circ} \mathrm{C}$ (centistokes) & ASTM-D2170 \\
\hline
\end{tabular}



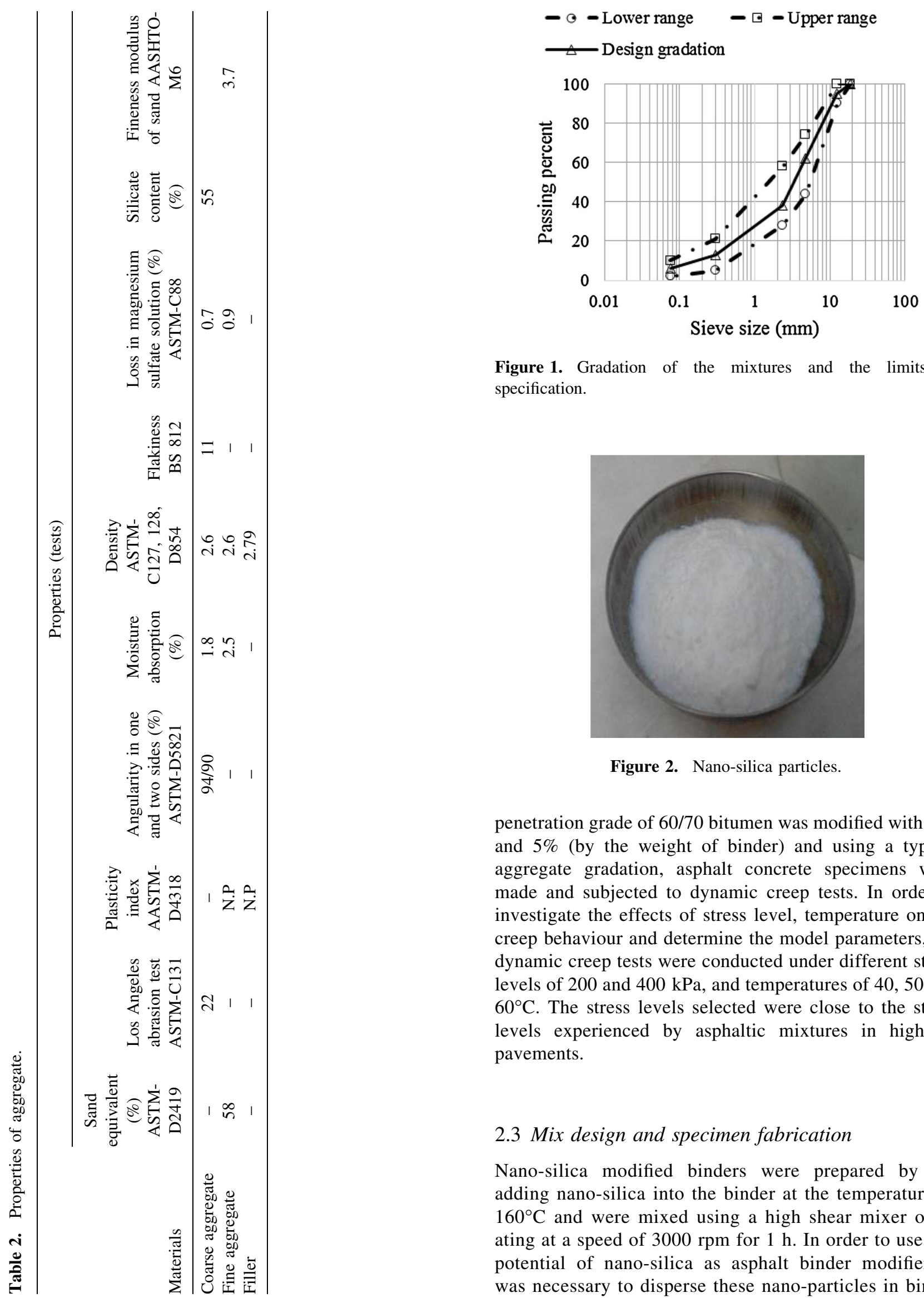

Figure 1. Gradation of the mixtures and the limits of specification.

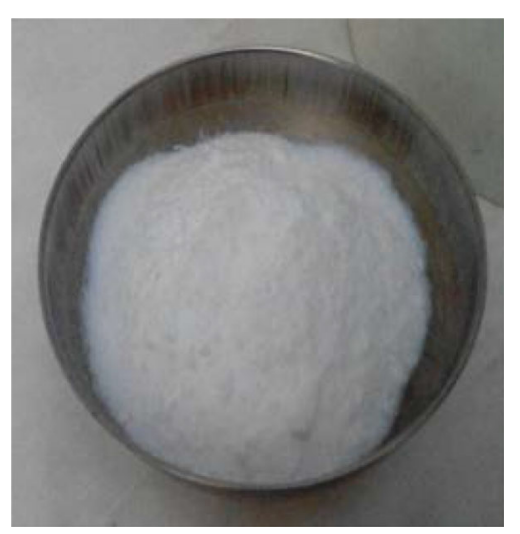

Figure 2. Nano-silica particles.

penetration grade of $60 / 70$ bitumen was modified with 1,3 and 5\% (by the weight of binder) and using a typical aggregate gradation, asphalt concrete specimens were made and subjected to dynamic creep tests. In order to investigate the effects of stress level, temperature on the creep behaviour and determine the model parameters, the dynamic creep tests were conducted under different stress levels of 200 and $400 \mathrm{kPa}$, and temperatures of 40,50 and $60^{\circ} \mathrm{C}$. The stress levels selected were close to the stress levels experienced by asphaltic mixtures in highway pavements.

\subsection{Mix design and specimen fabrication}

Nano-silica modified binders were prepared by the adding nano-silica into the binder at the temperature of $160^{\circ} \mathrm{C}$ and were mixed using a high shear mixer operating at a speed of $3000 \mathrm{rpm}$ for $1 \mathrm{~h}$. In order to use full potential of nano-silica as asphalt binder modifier, it was necessary to disperse these nano-particles in binder 
Table 3. Chemical composition and the properties of the nano-silica.

Chemical composition

\begin{tabular}{lcccc}
\hline $\begin{array}{l}\text { Composition } \\
\text { Value }\end{array}$ & $\begin{array}{c}\mathrm{SiO}_{2}(\%) \\
>99\end{array}$ & $\begin{array}{c}\mathrm{Ti}(\mathrm{ppm}) \\
<120\end{array}$ & $\begin{array}{c}\mathrm{Ca}(\mathrm{ppm}) \\
<70\end{array}$ & $\begin{array}{c}\mathrm{Na}(\mathrm{ppm}) \\
<50\end{array}$ \\
\hline Physical properties & \multicolumn{2}{c}{$\begin{array}{c}\mathrm{Fe}(\mathrm{ppm}) \\
<20\end{array}$} \\
\hline $\begin{array}{l}\text { True density }\left(\mathrm{gr} / \mathrm{cm}^{3}\right) \\
2.4\end{array}$ & $\begin{array}{c}\text { Bulk density }\left(\mathrm{gr} / \mathrm{cm}^{3}\right) \\
<0.1\end{array}$ & $\begin{array}{c}\text { Color } \\
\text { White }\end{array}$ & $\begin{array}{c}\text { SSA }\left(\mathrm{m}^{2} / \mathrm{g}\right) \\
200\end{array}$ & $\begin{array}{c}\text { Particle size }(\mathrm{nm}) \\
11-13\end{array}$ \\
\hline
\end{tabular}

Table 4. Creep tests conditions utilized in this study.

\begin{tabular}{lccccc}
\hline Stress level $(\mathrm{kPa})$ & Frequency $(\mathrm{Hz})$ & Loading time $(\mathrm{s})$ & Rest time $(\mathrm{s})$ & Number of cycles & Temperature $\left({ }^{\circ} \mathrm{C}\right)$ \\
\hline 200,400 & 0.5 & $1 \pm 0.05$ & $1 \pm 0.05$ & 10000 & $40,50,60$ \\
\hline
\end{tabular}

as much as possible. For making the asphalt concrete mixtures, by using the Marshall mix design method the optimum binder content of the control mixture (without nano-silica) was determined to be 5.3\%. The same binder content was used for making the specimens containing nano-silica. The specimens for the experiments of this research were made using Marshall compactor, according to ASTM D1559 standard method. Cylindrical specimens, measuring $101.6 \mathrm{~mm}$ in diameter and approximately $67 \mathrm{~mm}$ in height were fabricated. The required aggregates were weighed and heated in an oven at $172^{\circ} \mathrm{C}$ for $4 \mathrm{~h}$, and the asphalt cement was heated at $150^{\circ} \mathrm{C}$. Then, the heated aggregate and binder were mixed thoroughly using a small laboratory mixer. The mixture was placed in the Marshall compactor mold and compacted by the automatic compacter with 75 blows to either side. The specimens were removed from the mold after $24 \mathrm{~h}$ and used for the desired testing programme.

\section{Laboratory tests}

\subsection{Marshall test}

Marshall tests were conducted on the specimens of each mixture according to ASTM D1559 standard method. The specimens were placed in water tank set at $60^{\circ} \mathrm{C}$ for $30 \mathrm{~min}$, and loaded using Marshall test set-up, at a constant rate of $50.8 \mathrm{~mm} / \mathrm{min}$, and the force required for breaking the specimen was measured as the Marshall stability, and the diametrical deformation of the specimen at failure was measured as flow.

\subsection{Dynamic creep tests}

Different types of tests are available for the evaluation of the permanent deformation behaviour of asphaltic mixtures.
A common test method for evaluation of the permanent deformation of asphaltic mixtures is uniaxial dynamic creep test. In this study, dynamic creep tests were conducted on cylindrical specimens of the mixtures at different stress levels and temperatures. The tests were conducted using a UTM-10 machine, according to EN 12697-25 standard method [27]. Table 4 shows the creep tests conditions. For each test, the specimen was placed inside the temperature controlled cabinet for two hours before commencing the test, to ensure that the specimen is at uniform test temperature. A dummy specimen with a thermocouple in the center was used, which showed that in two hours the desired temperature could be reached. The test is controlled by the software installed on a PC connected to the test setup. As the permanent deformation of asphaltic mixtures occur at high temperatures, the tests were conducted at three different temperatures i.e., 40,50 and $60^{\circ} \mathrm{C}$. The tests were continued for 10000 loading cycles. During the testing period, the vertical deformation and stress level are monitored by the equipment software. Before starting the dynamic creep tests, to ensure that the loading plate is seated on the specimen, a static load with a magnitude of about $10 \%$ of the deviatoric stress was applied for $10 \mathrm{~min}$.

\section{Modelling creep curve}

Creep is a characteristic property of visco-elasto-plastic materials like asphaltic mixtures. Creep is the accumulation of deformation with time or loading cycles. Three distinguished regions of primary, secondary and tertiary can be defined in a creep curve. In primary region, the strain increases at a decreasing rate, until reaching to the secondary region, where the strain increases at a constant strain rate. At a certain number of cycles known as flow number, the tertiary region begins in which the strain increases at an increasing rate of cycles. Modelling the creep behaviour of asphaltic mixtures can be useful in the investigations and predictions of 
Table 5. Marshall stability and flow of the mixtures.

\begin{tabular}{lcccc}
\hline Mixture & Base & NS1\% & NS3\% & NS5\% \\
\hline Marshall stability $(\mathrm{kN})$ & 14.38 & 14.77 & 15.2 & 16.23 \\
Flow $(\mathrm{mm})$ & 2.97 & 2.5 & 2.23 & 2.15 \\
\hline
\end{tabular}

the rutting of asphaltic pavements. Different mathematical models have been suggested for capturing the creep behaviour of asphaltic materials and prediction of flow number. A review of these models can be found elsewhere [28].

The main features of a creep curve of an asphaltic mixture are, the time or the number of loading cycle at which, the secondary creep region begins, the constant strain rate in the secondary region, and the flow number. Determination of these features can be useful for the investigation of the rutting of asphaltic pavements. Flow number is commonly used as a criterion for comparing the rutting potential of asphaltic mixtures [6]. The steady-state strain rate, also known as creep strain slope (CSS) is related to the permanent deformation behaviour of asphaltic mixtures [29].

A three-stage model has been suggested by Zhou et al [30], for modelling each region of the creep curve of asphaltic mixtures. They have also suggested an algorithm for estimating the number of cycles at the beginning of the secondary and tertiary region. Equations (1)-(3) show their models for the primary, secondary and tertiary region, respectively. The primary, secondary and tertiary regions were modelled by power, linear and exponential functions, respectively.

$$
\begin{gathered}
N \leq N_{p s}, \quad \varepsilon_{p}=a N^{b} \\
\varepsilon_{p}=\varepsilon_{P S}+c\left(N-N_{P S}\right), \quad N_{P S} \leq N \leq N_{S T} \text { and } \varepsilon_{P S}=a N_{P S}^{b}
\end{gathered}
$$

$$
\begin{aligned}
& \varepsilon_{p}=\varepsilon_{S T}+d\left(e^{f\left(N-N_{S T}\right)}-1\right) \\
& N \geq N_{S T} \text { and } \varepsilon_{S T}=\varepsilon_{P S}+c\left(N_{S T}-N_{P S}\right)
\end{aligned}
$$

where, $\mathrm{a}, \mathrm{b}, \mathrm{c}, \mathrm{d}$ and $\mathrm{f}$ are material constants, $\varepsilon_{p}$ is plastic strain, $\mathrm{N}$ is the number of cycles, $N_{P S}$ is the number of cycles at the beginning of the secondary region, $N_{S T}$ is the number of cycles at the beginning of the tertiary region, $\varepsilon_{P S}$ is the accumulated plastic strain at the beginning of the secondary region and $\varepsilon_{S T}$ is the accumulated plastic strain at the beginning of the tertiary region [30].

In this study, the three-stage model was utilized for calculation of the flow number $\left(N_{S T}\right)$, the number of cycles at the beginning of the secondary region $\left(N_{P S}\right)$, and the creep strain slope (CSS) of the nano-silica modified asphaltic concrete at different stress levels and temperatures. Using MATLAB, the models were fitted to the primary, secondary and tertiary creep regions resulted from dynamic creep tests, and the model constants, $N_{P S}, N_{S T}$ and CSS were determined for each mixture at different test conditions. For brevity, the algorithm for determination of the constants is not presented here. The interested readers can find it elsewhere [30].

\section{Test results}

\subsection{Marshall test results}

Table 5 shows the Marshall stability and flow of the mixtures containing different nano-silica contents. The Marshall stability of each mixture was obtained by averaging the results of the test conducted on three specimens. As can be seen, Marshall stability increases with increasing nanosilica content, with the highest stability for the mixture containing $5 \%$ of nano-silica. Iranian asphalt pavement specification requires a minimum Marshall stability of $8.5 \mathrm{kN}$ for heavy traffic applications. The flow of the mixtures, which is used as an indication of ductility of asphaltic mixtures, is also shown in table 5. Flow is an indication of the ductility of asphaltic mixtures. A minimum flow of 2 and a maximum flow of $3.5 \mathrm{~mm}$ are required by specifications to guarantee resistance against cracking and permanent deformation, respectively. As can be seen in table 5, nano-silica modification results in the decrease of flow, which decreases with increasing nanosilica content. However, all mixtures satisfy the requirements of specification.

\subsection{Creep test results}

As mentioned earlier, dynamic creep tests were conducted on the specimens of the control and nano-silica modified mixtures at different stress levels and temperatures. In order to investigate the stress dependency of the creep behaviour of the mixtures, the tests were conducted on the control mixture and the mixtures containing 1,3 and $5 \%$ of nano-silica content at $50^{\circ} \mathrm{C}$ and stress levels of 200 and $400 \mathrm{kPa}$. In addition, to investigate the temperature sensitivity, the dynamic creep tests were conducted on the control mixture and the mixture containing the optimum nano-silica content at 40 and $60^{\circ} \mathrm{C}$ and stress level of $200 \mathrm{kPa}$.

Figure $3 \mathrm{a}$ and $3 \mathrm{~b}$ shows the dynamic creep test results on the control and nano-silica modified mixtures subjected to the stress levels of 200 and $400 \mathrm{kPa}$, respectively, at the temperature of $50^{\circ} \mathrm{C}$, where the accumulated vertical strain is plotted against the number of cycles. As can be seen, 

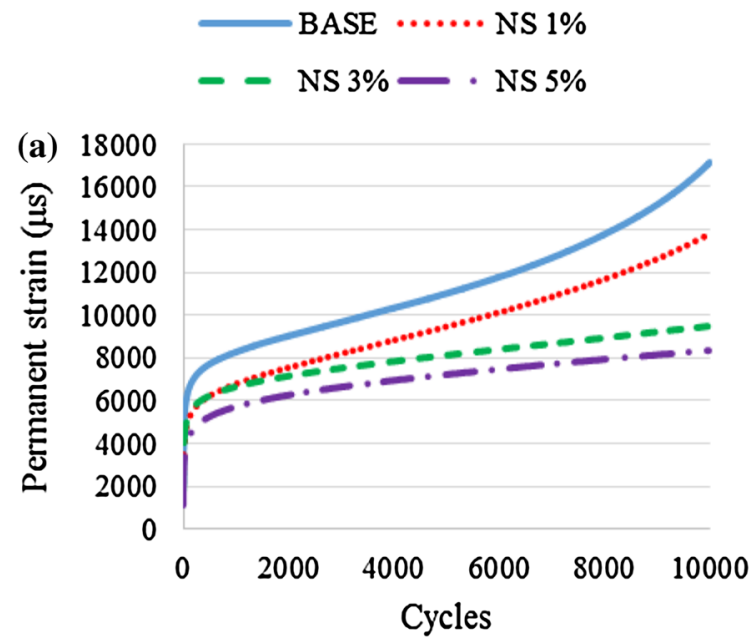
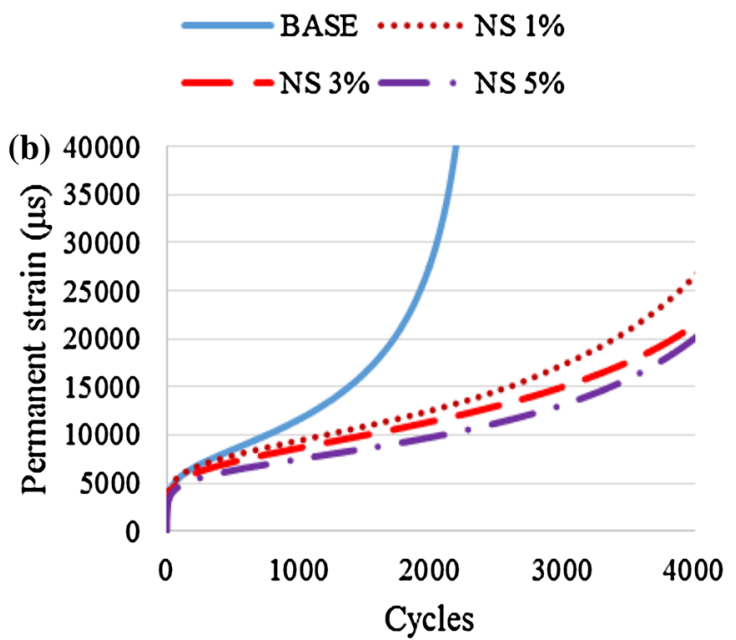

Figure 3. Creep curves of the mixtures subjected to (a) $200 \mathrm{kPa}$ and (b) $400 \mathrm{kPa}$ at $50^{\circ} \mathrm{C}$.

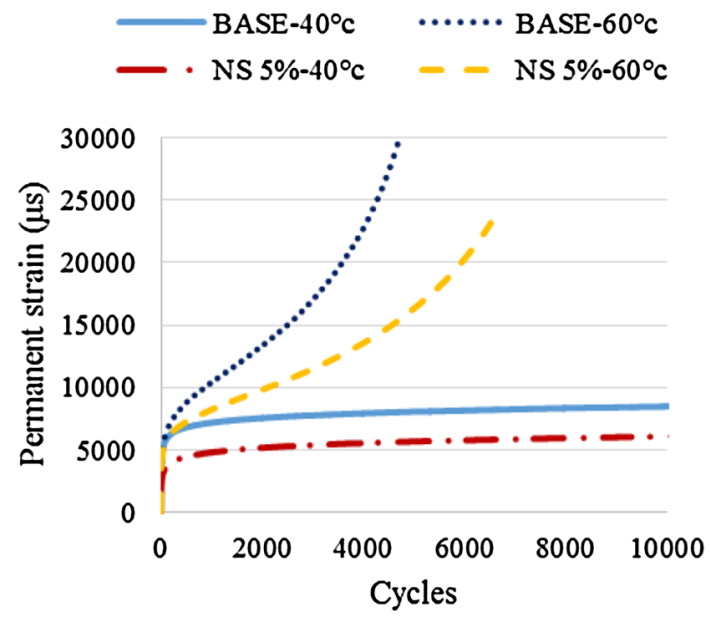

Figure 4. Creep curves of the control mixture and the mixture containing $5 \%$ of nano-silica subjected to $200 \mathrm{kPa}$ at 40 and $60^{\circ} \mathrm{C}$.

under both 200 and $400 \mathrm{kPa}$, the accumulated vertical strain of the mixtures decreases with increasing nano-silica content, indicating that the resistance against permanent deformation increases by using nano-modified binder in the mixture. As can be seen, under the stress level of $200 \mathrm{kPa}$, the mixture containing 3 and 5\% do not reach the tertiary creep region where the mixture loses its integrity and the accumulation of permanent strain accelerates. From the results presented in figure 3 , it can be seen that, over the range of nano-silica contents used in this research, the optimum nano-silica content for achieving the highest resistance against permanent deformation is $5 \%$. Therefore, in order to investigate the effects of temperature on the resistance against permanent deformation, the dynamic creep test was conducted on the mixture containing $5 \%$ of nano-silica at 40 and $60^{\circ} \mathrm{C}$ and subjected to $200 \mathrm{kPa}$, and

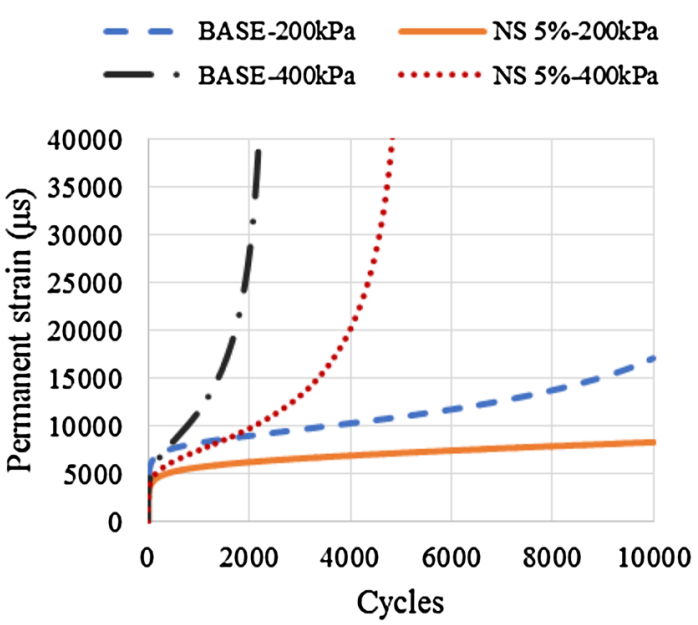

Figure 5. Creep curves of the control mixture and the mixture containing $5 \%$ of nano-silica subjected to $200 \mathrm{kPa}$ and $400 \mathrm{kPa}$ at $50^{\circ} \mathrm{C}$.

compared with the control mixture. Figure 4 shows the dynamic creep test results of the control mixture and the mixture modified with $5 \%$ of nano-silica at 40 and $60^{\circ} \mathrm{C}$ and subjected to the stress level of $200 \mathrm{kPa}$. The effect of increasing temperature on the permanent deformation of the control mixture is considerably higher than that of the mixture modified by $5 \%$ of nano-silica, indicating that nano-silica modified asphaltic mixtures were less prone to the rutting at high temperatures, and was shown that the temperature susceptibility of the binder decreased with increasing nano-silica content.

Figure 5 shows the creep curves of the control mixture and the mixture containing $5 \%$ of nano-silica under the stress levels of 200 and $400 \mathrm{kPa}$ at $50^{\circ} \mathrm{C}$, where the accumulated strain increases nonlinearly with increasing stress level. It is also obvious that the difference between the 


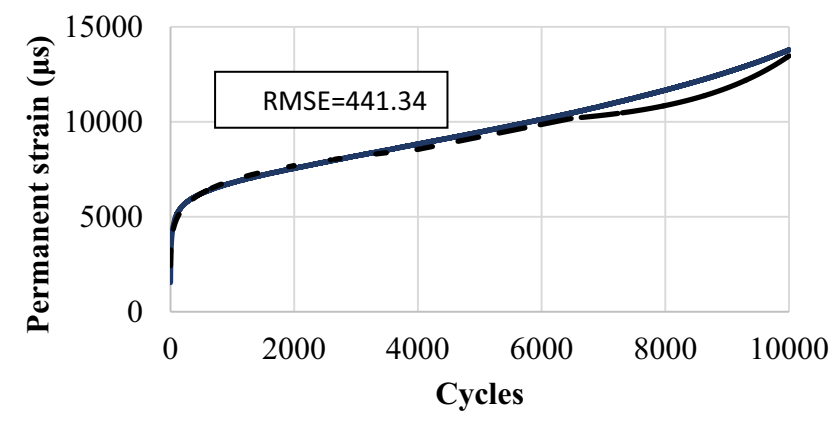

- experimental results $\quad-$ predicted results by model

Figure 6. Fitting the models to the primary, secondary and tertiary creep regions of the mixture containing $1 \%$ of nano-silica.

accumulated strain of the modified and control mixture is higher at the higher stress level of $400 \mathrm{kPa}$ than at $200 \mathrm{kPa}$, indicating that nano-silica modification is more effective on the resistance against permanent deformation under heavier loading.

\subsection{Creep curve modelling}

Using MATLAB, the three-stage model, developed by Zhou et al [30] Eqs. (1) to (3), was fitted to the primary, secondary and tertiary creep regions of the creep curves of the mixtures and the model constants were determined. As an example, figure 6 shows fitting the models to the primary, secondary and tertiary creep regions of the mixture containing $1 \%$ of nano-silica. As can be seen, the model well-fitted to the experimental results. The root-meansquared-error (RMSE) of this creep results was determined, which is shown on figure 6 , indicates that the errors in prediction of creep results are acceptable. This is also confirmed as presented in table 6 which shows the models for the primary, secondary and tertiary regions for different tests conditions utilized in this study on the control and nano-silica modified mixtures. From the $\mathrm{R}^{2}$ values of the models presented in table 5 , the results show that the creep curves of all testing conditions are well-captured by the three-stage model and the strains predicted by the models are comparable with test results.

Utilizing the algorithm developed by Zhou et al [30], the flow number, the creep stain slope (CSS), which is the steady state strain rate in the secondary creep region and the number of cycles at the beginning of the secondary creep region were also determined, which are presented in table 6 . The results show that, at the same stress and temperature, the number of cycles at the beginning of the secondary creep region and the flow number increase with increasing nano-silica content of the mixtures. As the majority of the time-dependent strain occurring in the first region is recoverable after removing the stress, this is in favor of resistance against permanent deformation. Also, the sensitivity to temperature and stress

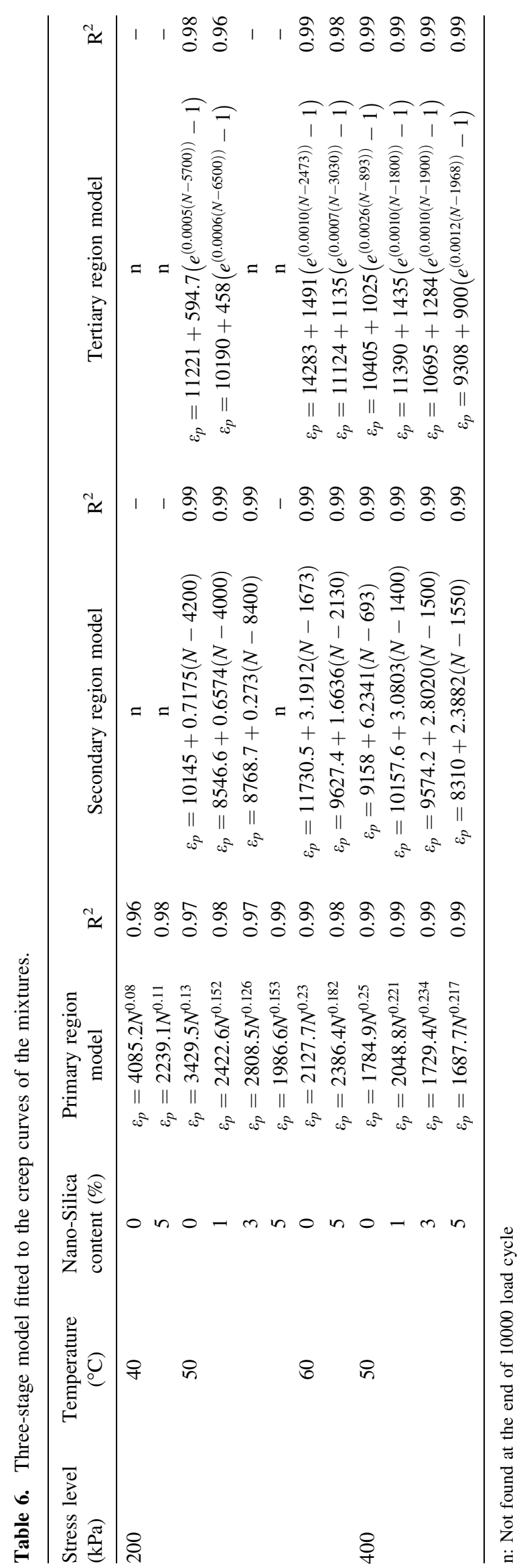


Table 7. The creep curve parameters of the mixtures in different conditions.

\begin{tabular}{lcccrl}
\hline $\begin{array}{l}\text { Stress } \\
\text { level } \\
(\mathrm{kPa})\end{array}$ & $\begin{array}{c}\text { Temperature } \\
\left({ }^{\circ} \mathrm{C}\right)\end{array}$ & $\begin{array}{c}\text { Nano- } \\
\text { silica } \\
\text { content } \\
(\%)\end{array}$ & $\begin{array}{c}\text { Number } \\
\text { of load } \\
\text { cycles at } \\
\text { first stage }\end{array}$ & $\begin{array}{c}\text { Flow } \\
\text { number }\end{array}$ & $\begin{array}{l}\text { clope } \\
\text { strain }\end{array}$ \\
\hline 200 & 40 & 0 & $\mathrm{n}$ & $\mathrm{n}$ & $\mathrm{n}$ \\
& & 5 & $\mathrm{n}$ & $\mathrm{n}$ & $\mathrm{n}$ \\
& 50 & 0 & 4200 & 5700 & 0.7175 \\
& & 1 & 4000 & 6500 & 0.6574 \\
& & 3 & 8400 & $\mathrm{n}$ & 0.273 \\
& & 5 & $\mathrm{n}$ & $\mathrm{n}$ & $\mathrm{n}$ \\
& 60 & 0 & 1673 & 2473 & 3.1912 \\
400 & 50 & 5 & 2130 & 3030 & 1.6636 \\
& & 0 & 693 & 893 & 6.2341 \\
& & 1 & 1400 & 1800 & 3.0803 \\
& & 3 & 1500 & 1900 & 2.8020 \\
& & 5 & 1550 & 1968 & 2.3882 \\
\hline
\end{tabular}

level of the number of cycles at the beginning of the secondary region and flow number decrease with increasing nano-silica content. Subjected to the stress level of $200 \mathrm{kPa}$, while the control mix do not go through the secondary creep region at $40^{\circ} \mathrm{C}$, at 50 and $60^{\circ} \mathrm{C}$, all stages of creep can be recognized, indicating that the control mixture is highly susceptible to temperature and prone to rutting at high temperatures. However, under the same stress level, the mixture containing $5 \%$ of nano-silica do not go through the secondary creep region at both 40 and $50^{\circ} \mathrm{C}$, and, at $60^{\circ} \mathrm{C}$, the number of cycles required to go through the tertiary creep region is approximately $22 \%$ higher than that for the control mixture, and the length of the primary region is $27 \%$ higher than that of the control mixture. When subjected to the stress level of $200 \mathrm{kPa}$, the flow number of the control mixture and the mixture containing $1 \%$ of nano-silica are 6.38 and 3.61 times, higher than those subjected to the stress level of $400 \mathrm{kPa}$. For investigating the stress dependency, creep tests were conducted on the mixtures by applying 200 and $400 \mathrm{kPa}$ stress level. These results show that the nano-silica modified mixtures are less susceptible to stress level than the control mixture.

The results in table 7 show that the steady state strain rate in the secondary creep region (CSS), which is an index for visco-plastic deformation of asphaltic mixtures, which increases with increasing temperature and stress level. Although the results are not enough to describe the temperature sensitivity of CSS for the nano-silica modified mixtures, the creep strain slope of the nano-silica modified mixtures are less susceptible to stress level than the control mixture. Also, the secondary creep strain decreases with increasing nano-silica content. Comparison of the creep stain slope of the mixtures at the stress levels of 200 and $400 \mathrm{kPa}$ shows that the variation of this parameter with stress level is not linear. Also, the creep strain slope in region 2 decreases with increasing nanosilica content.

\section{Conclusions}

Based on the range of nano-silica contents used in this research, and the results of the tests conducted, the following conclusions are drawn.

- The stiffness of asphalt increased and its temperature sensitivity decreased with increasing nano-silica content, indicating that the nano-silica modification improved the resistance against permanent deformation and low temperature cracking of asphalt cement.

- The results of dynamic creep tests shown that the resistance against permanent deformation increased with increasing nano-silica content.

- The mixtures containing nano-silica has shown more resistance against permanent deformation under high temperatures and stress levels.

- Three-stage model was well fitted to the dynamic creep tests results, by which the number of cycles at the beginning of the primary creep region, flow number and steady-state strain rate were determined.

- The results have shown that the number of cycles at the beginning of the primary creep region and flow number increased, and the steady-state strain rate decreased with increasing nano-silica content.

- Nano-silica modification decreased the temperature and stress sensitivity of the length of primary creep region and flow number.

- Nano-silica modification decreased the stress sensitivity of the creep strain slope of the mixture.

\section{References}

[1] Isacsson U and $\mathrm{Lu} \mathrm{X} 1995$ Testing and appraisal of polymer modified road bitumens-state of the art. Mater. Struct. 28: 139-159

[2] Airey G D 2003 Rheological properties of styrene butadiene styrene polymer modified road bitumens. Fuel 82(1): 709-719

[3] Yusoff N I M, Breem A A S, Alattug H N M, Hamim A and Ahmad J 2014 The effects of moisture susceptibility and ageing conditions on nano-silica/polymer-modified asphalt mixtures. J. Constr. Build. Mater. 72: 139-147

[4] Whiteoak D and Read J 2005 Shell bitumen handbook. UK, London: Shell Bitumen

[5] Isacsson U and Zeng H 1998 Low-temperature cracking of polymer-modified asphalt. J. Mater. Struct. 31(1): 58-63

[6] Yao H, You Z, Li L, Lee C H, Wingard D, Yap Y K, Shi X and Goh S W 2013 Rheological properties and chemical bonding of asphalt modified with nanosilica. J. Mater. Civil Eng. 25(11): 1619-1630 
[7] Scientific Committee on Emerging and Newly Identified Health Risks (SCENIHR) 2006 Modified opinion (after public consultation) on the appropriateness of existing methodologies to assess the potential risks associated with engineered and adventitious products of nanotechnologies. European Commission Health \& Consumer Protection Directorate-General

[8] Liu Y L, Hsu C Y, Wei W L and Jeng R J 2003 Preparation and thermal properties of epoxy-silica nanocomposites from nanoscale colloidal silica. Polymer 44: 123-129

[9] [9] Jahromi S G, Andalibizade B and Vossough S 2010 Engineering properties of nanoclay modified asphalt concrete mixtures. Arabian J. Sci. Eng. 35(1B): 89-103

[10] Shafabakhsh G H, Mirabdolazimi S M and Sadeghinejad M 2015 Evaluation the effect of nano- $\mathrm{TiO}_{2}$ on the rutting and fatigue behavior of asphalt mixtures. J. Construct. Build. Mater. 54: 566-572

[11] Shafabakhsh G H and Jafari Ani O 2015 Experimental investigation of effect of $\mathrm{Nano}_{\mathrm{TiO}} / \mathrm{SiO}_{2}$ modified bitumen on the rutting and fatigue performance of asphalt mixtures containing steel slag aggregates. J. Construct. Build. Mater. 85: 136-143

[12] You Z, Mills-Beale J, Foley J M, Roy S, Odegard G M, Dai Q and Goh S W 2011 Nanoclay-modified asphalt materials: Preparation and characterization. Construct. Build. Mater. 25(2): 1072-1078

[13] Khattak M J, Khattab A, Rizvi H R and Zhang P 2012 The impact of carbon nano-fiber modification on asphalt binder rheology. Construct. Build. Mater. 30(5): 257-264

[14] Ghile D B 2006 Effects of nanoclay modification on rheology of bitumen and on performance of asphalt mixtures. Delft, The Netherlands: Delft University of Technology

[15] Becker Y, Méndez M P and Rodriguez Y 2001 Polymer modified asphalt. Vis. Technol. 9(1): 39-50

[16] Santagata E, Baglieri O, Tsantilis L and Dalmazzo D 2012 Rheological characterization of bituminous binders modified with carbon nanotubes. Proc. Social Behav. Sci. 53: 546-555

[17] Jahromi S G and Khodaii A 2009 Effects on nanoclay on rheological properties of bitumen binder. Construct. Build. Mater. 23: 2894-904

[18] Polacco G, Kriz P, Filippi S, Stastna J, Biondi D and Zanzotto L 2008 Rheological properties of asphalt/SBS/clay blends. Eur. Polym. J. 44: 3512-3521
[19] Sureshkumar M S, Filippi S, Polacco G, Kazatchkov I, Stastna J and Zanzotto L 2010 Internal structure and linear viscoelastic properties of EVA/asphalt nanocomposites. Eur. Polym. J. 46(4): 621-633

[20] Han N F, Zhou D J and Tang X D 2011 Effect of nano calcium carbonate and montmorillonite on properties of styrene-butadiene-styrene copolymer modified asphalt. J. Appl. Mech. Mater. 99: 1035-1038

[21] Hao X H, Zhang A Q and Yang W 2012 Study on the performance of nano calcium carbonate modified asphalt concrete AC-13. Adv. Mater. Res. 450: 503-507

[22] Yang J and Tighe S 2013 A review of advances of Nanotechnology in asphalt mixtures. Procedia-Social Behav. Sci. 96: 1269-1276

[23] Barik T K, Sahu B and Swain V 2008 Nanosilica-from medicine to pest control. Parasitol. Res. 103(2): 253-258

[24] Chrissafis K, Paraskevopoulos K M, Papageorgiou G Z and Bikiaris D N 2008 Thermal and dynamic mechanical behavior of bionanocomposites: fumed silica nanoparticles dispersed in poly (vinyl pyrrolidone), chitosan, and poly(vinylalcohol). J. Appl. Polym. Sci. 110: 1739-1749

[25] Quercia G and Brouwers H J H 2010 Application of nanosilica (nS) in concrete mixtures. In: 8th fib PhD symposium in Kgs, Lyngby, Denmark

[26] Lazzara G and Milioto S 2010 Dispersions of nano-silica in biocompatible copolymers. Polym. Degrad. Stab. 95: 610-617

[27] CEN EN 12697-25:2016 Bituminous mixtures-test methods. Cyclic compression test, Brussels, CEN

[28] Khodaii A and Mehrara A 2009 Evaluation of permanent deformation of unmodified and SBS modified asphalt mixtures using dynamic creep test. Construct. Build. Mater. 23(7): 2586-2592

[29] Grenfell J R A, Taherkhani H, Collop A C, Airey G D and Scarpas A 2008 Deformation Characterisation of Asphalt Concrete Behaviour (With Discussion). J. Assoc. Asphalt Paving Technologists. 77

[30] Zhou F, Scullion T and Sun L 2004 Verification and modeling of three-stage permanent deformation behavior of asphalt mixes. J. Transport. Eng. 130(4): 486-494 